\title{
THE DUAL CIRCULATION OF THE LUNGS AND THEIR CONNECTIONS
}

\author{
L. BÜTOW, B.Sc. in Physiotherapy (Stell.)*
}

\section{SUMMARY}

The bronchial and pulmonary circulations are outlined and their relevance to certain pathological conditions is conjectured.

\section{INTRODUCTION}

The main function of the lung is respiration. Here, the distribution of the blood is just as important as the distribution of the air. It could be said that disturbance in the ventilation/perfusion balance is probably the $\therefore \mathrm{st}$ common cause of respiratory failure in patients Wil lung disease (Meyer, 1976). Knowledge of the bronchial and pulmonary circulation, and their different reactions to hypoxia, is thus very important in understanding the way in which certain existing communications between the two systems come into play and the effect thereof under certain pathological conditions.

\section{ANATOMY}

\section{Bronchial and pulmonary circulation}

The lung is supplied by a small bronchial and a large pulmonary arterial system. The bronchial arteries are usualiy direct branches from the descending aorta (usually one on the right and two on the left), but there may be variations in their origin. They supply the smooth muscle of the bronchi from the carina to the respiratory bronchioles and also nourish the connective tissue in this area as well as certain parts of the visceral pleura (Last, 1972). The middle segment of the oesophagus, a part of the vagus nerve and the tracheobronchial lymph nodes are also supplied by the bronchial arteries. In addition, there are vasa vasorum in close contact with and supplying the pulmonary arteries.

The bronchial arteries divide into numerous branches

Seminar presented for M.Sc. in Physiotherapy I, Departments of Anatomv and Physiotherapy, University of Stellenbosch, 1978.

Received 16 July 1980.

\section{OPSOMMING}

Die brongiale en pulmonale sirkulasies word beskryf en die moontlike verband ten opsigte van sekere patologiese toestande word aangedui.

before reaching the respiratory bronchioli - the socalled broncho-pulmonary branches. These branches divide further into lobular and eventually into bronchial capillaries which join up with the pulmonary capillaries. Together they drain into the pulmonary veins. The bronchial capillaries usually supply the bronchioli although the pulmonary arteries or even the pulmonary veins may also perform this task (Tobin, 1952). The bronchial arteries are part of the systemic circulation and their blood pressure $(120 / 80 \mathrm{mmHg})$ is therefore more or less five times greater than that of the pulmonary arteries $(25 / 10 \mathrm{mmHg})$. The bronchial arteries tend to spiral around the bronchioles and are thus arranged in a dense communicating network. This plexiform arrangement of the bronchial arteries is the reason why the systemic arterial supply to a bronchus is not easily cut off (Liebow, 1949).

The bronchial veins also form a network around the bronchi. The veins which drain the first part of the bronchi (extrapulmonary) drain into the right atrium via the azygos (right) and hemiazygos (left) veins. The rest of the bronchial veins enter the pulmonary veins on their way to the left atrium and their contents make up more or less $2 \%$ of the cardiac output (Meyer, 1976). These bronchial venous plexi may anastomose with the venous (pulmonary) capillaries around the alveoli, or they may connect by branches to the pulmonary veins (post-capillary), or they may even anastomose with adjacent parts of the bronchial venous plexi so that the blood may drain upwards into the azygos system (Tobin, 1952).

The pulmonary trunk which gives rise to the pulmonary arteries originates from the right ventricle and bifurcates, sending one branch to each lung. The pulmonary arteries have a rectilinear course roughly parallel to the branches of the respiratory tree. They are true end-arteries, connecting only in the finer capillary networks (Liebow, 1949). The pulmonary arterioles and

\section{Contents - Inhoud}

The Dual Circulation of the Lungs and their connections

Ascultation of the Chest $\ldots \ldots \ldots \ldots, \ldots \ldots \ldots$

The Value of a Home Treatment Programme for Paediatric Patients with Respiratory Disorders ...

Shortwave Diathermy (SWD) in the Treatment of

Unresolved Pneumonia
The Critical Incident Technique in Physiotherapy $\begin{array}{llllllllllllll}\text { Education } & \ldots & \ldots & \ldots & \ldots & \ldots & \ldots & \ldots & \ldots & \ldots & \ldots & \ldots & \ldots & 73\end{array}$

Straight Leg Raise as a Treatment Technique ... 74

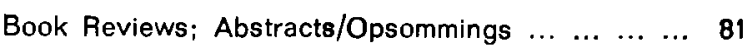

$\begin{array}{lllllllllllllllll}\text { Classified } & \ldots & \ldots & \ldots & \ldots & \ldots & \ldots & \ldots & \ldots & \ldots & \ldots & \ldots & \ldots & \ldots & 85\end{array}$

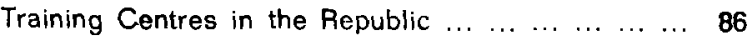


capillaries are short and their diameters relatively wide so that there is a decreased resistance to blood flow and this system is thus one of passive low pressure. The capillaries form a rich plexus around each alveolus and they supply the alveoli with all their needs, excluding oxygen. When a bronchus is obstructed, the pulmonary vessels supplying the poorly ventilated alveoli react to the hypoxia by constricting and shunting the blood to other areas. (The bronchial arteries dilate with hypoxia). Emboli that block small branches of the pulmonary artery provoke a marked rise in pulmonary arterial pressure, although this is absent when larger arteries are blocked (Ganong, 1973), but there is some controversy about this. There are usually two pulmonary veins from each lung, carrying oxygenated blood to the left atrium (Last, 1972). The blood is not $100 \%$ saturated with oxygen as there is mixing with venous blood from the bronchial veins.

The pulmonary capillary pressure is about $10 \mathrm{mmHg}$ and the oncotic pressure about $25 \mathrm{mmHg}$. There is thus an inward-outward pressure gradient of about 15 $\mathrm{mmHg}$ which keeps the alveoli free of fluid. If the pulmonary capillary pressure exceeds $25 \mathrm{mmHg}$ (failure of left ventricle), this gradient will shift and oedema and pulmonary congestion will develop (Ganong, 1973).

\section{Pleural fluid}

Pleural fluid moves into the pleural cavity under the influence of the parietal pleural layer and is absorbed by the visceral layer.

Fluid entering the pleural space depends on the following pressure gradients:

\section{Parietal pleural layer}

Factors causing fluid to enter the pleural space: Hydrostatic pressure (in arterial capillary) $=30 \mathrm{~cm} \mathrm{H}_{2} \mathrm{O}$ + Negative pleural pressure

$$
=\frac{5 \mathrm{~cm} \mathrm{H}_{2} \mathrm{O}}{=35 \mathrm{~cm} \mathrm{H}_{2} \mathrm{O}}
$$

Total

Factors keeping fluid out of the pleural space:

Oncotic pressure (in capillary)

$$
=34 \mathrm{~cm} \mathrm{H}_{2} \mathrm{O}
$$

- Oncotic pressure (in pleural fluid)

$$
=8 \mathrm{~cm} \mathrm{H}{ }_{2} \mathrm{O}
$$

Total

$$
=\longdiv { 2 6 \mathrm { cm } \mathrm { H } _ { 2 } \mathrm { O } }
$$

The force responsible for moving the fluid into the cavity is thus $35 \mathrm{~cm} \mathrm{H}_{2} \mathrm{O}$ and the force for absorbing the fluid is only $26 \mathrm{~cm} \mathrm{H}_{2} \mathrm{O}$. There is thus a resultant force of $9 \mathrm{~cm} \mathrm{H}, \mathrm{O}$ in the direction of the pleural cavity.

\section{Visceral pleural layer}

The fluid absorbed by the visceral layer depends on the following pressure gradients:

Factors keeping fluid in pleural space:

Hydrostatic pressure (in capillary)

+ Negative pleural pressure

$$
\begin{aligned}
& =1 \mathrm{I} \mathrm{cm} \mathrm{H}_{0} \mathrm{O} \\
& =5 \mathrm{~cm} \mathrm{H} \mathrm{H}_{2} \mathrm{O} \\
& =\longdiv { 1 6 \mathrm { cm } \mathrm { H } \mathrm { O } }
\end{aligned}
$$

Total

$=34 \mathrm{~cm} \mathrm{H}_{2} \mathrm{O}$

Factors for absorbing fluid:

Oncotic pressure (in capillary)

- Oncotic pressure (in pleural fluid)

Total

$$
\begin{aligned}
& =34 \mathrm{~cm} \mathrm{H}_{2} \mathrm{O} \\
& =\frac{8 \mathrm{~cm} \mathrm{H} \mathrm{H}_{2} \mathrm{O}}{=26 \mathrm{~cm} \mathrm{H} \mathrm{H}_{2} \mathrm{O}}
\end{aligned}
$$

The total force is thus $10 \mathrm{~cm} \mathrm{HoO}$ in the direction of the visceral layer and the fluid is absorbed.

\section{Lung zones}

The transmural pressure of the pulmonary arteries is the result of the perivascular pressure and the intravascular pressure. This resultant force is dependent on gravity; in the upright position the blood pressure is maximum at the lung bases. The vessels are therefore dilated at the bases and narrower at the apices. The capillaries in the apex (Zone I) are thus the first to collapse if the capillary pressure should decrease below that of the alveolar pressure. This does not usually occur under normal conditions, but when there is a fall in arterial pressure (e.g. haemorrhage) or a rise in the alveolar pressure (e.g. the use of positive pressure ventilation) it may happen. In the middle lung regions (Zone II) the arterial capillary pressure is greater than the alveolar pressure and the alveolar pressure is greater than the venous capillary pressure. There is thus less likelihood of the arterial capillaries in this area collapsing than in Zone $\mathrm{I}$. The blood flow in this area is dependent on the arterial-alveolar gradient (not the usual arterialvenous gradient). In Zone III (bases) no collapse of capillaries takes place, as the capillary arterial pressure is greater than that of the alveolar pressure and the alveolar pressure is smaller than that of the venous capillapi pressure. Here the blood flow is dependent on th pressure. Here the blood flow is 1976 and West, 1974).

\section{Arterio-arterial and arterio-venous communications}

It is generally accepted that there is some overspill of bronchial capillaries into alveolar (pulmonary) capillaries (Last, 1972). However, it has recently also been proved that precapillary anastomoses between bronchial arteries and pulmonary arteries do exist. There are two types of these anastomoses, namely the short $1-2 \mathrm{~mm}$ ). narrow $(50-100$ micron) type which lies peripherally, and the long $(10-40 \mathrm{~mm})$, wide $(300-400$ micron) type which are more centrally situated. These anastomoses have coiled, thick muscle walls which reduce the blood pressure from the bronchial to the pulmonary arterial system (Tobin, 1952). During deep inspiration, the decreased pressure in the pulmonary artery will cause more blood to flow into it from the bronchial arteries through the precapillary arterio-arterial shunts (Pump, 1972).

Obstruction of the bronchial arteries themselves may lead to necrosis of the extrapulmonary bronchi but not of the intrapulmonary bronchi because of their connections with other blood vessels (Tobin, 1952).

Apart from these arterio-arterial anastomoses, there are also arterio-venous connections between the pulmonary arteries and the pulmonary veins. Anatomically it has been seen that there is an arterial loop at the apex of the acinus and that this loop has very lis muscle or elastic tissue in its wall. This segment may be. dilated to form glomus-like protrusions or to allow the passage of glass spheres, $200 \mu$ in diameter and many times the accepted diameter of the capillaries, into the pulmonary veins (Tobin, 1966). In the foetus these arterio-venous shunts may play a role in diverting the blood from the pulmonary arteries (and their connections with the bronchial arteries) into the pulmonary veins. The unexpanded alveoli are thus avoided (Tobin, 1952). In normal, resting subjects with no intracardiac shunts, this arterio-venous pulmonary shunt flow averages $1 \%$ of the total pulmonary blood flow. When using the Valsalva technique on patients, there is a rise in oxygen saturation during the manoeuvre, and a fall in saturation following release of this technique. The saturation rise averages $1,2 \%$ in normal people; in patients with cardiac or pulmonary disease this value is even higher, namely $3,9-7,5 \%$. It is supposed that this manoeuvre leads to a fall in transmural pressure in the pulmonary artery with a decreased blood flow in the pulmonary arterial as well as in the arterio-venous shunts. The result is that more blood flows through the capillaries and that more blood becomes oxygenated, which causes the rise in oxygen saturation. This does not, however, always apply to patients with con- 
gestive heart failure in whom the Valsalva technique might have no effect on transmural pressure of the pulmonary artery (José and Milner, 1959).

\section{PATHOLOGICAL CONDITIONS}

\section{Pulmonary embolism}

When a pulmonary artery and vein of a lobe in a dog's lung are both occluded, the vascular pressures within that lobe rise to abnormally high levels (Shedd et al., 1951). The reason for this is that the pulmonary artery responds to the hypoxia by constricting and shunting the blood away from that area, while the bronchial artery (like any other systemic artery) responds by dilating. An extensive opening of the precapillary anastomoses takes place between the bronchial and pulmonary arteries. The high blood pressure of the bronchial arteries is thus transmitted to the pulmonary arteries. The increased hydrostatic pressure of the pulmonary arteries is no longer $11 \mathrm{~cm} \mathrm{H}_{2} \mathrm{O}$, but may be y value up to more or less $30 \mathrm{~cm} \mathrm{H}_{2} \mathrm{O}$, and the Nsceral pleura, supplied by the pulmonary arteries, no longer has a driving force to absorb the pleural fluid. That is why a pulmonary embolus is usually associated with a pleural effusion.

\section{Pneumonia}

There is a period of hypoxia (anoxia) during pneumonia, and the pulmonary arteries supplying the region react by constricting and shunting the blood to other areas. It is to be expected that these parts would thus die as they are deprived of their blood supply. However, the dilation of the bronchial arteries and associated arterio-arterial anastomoses causes the blood to be shunted to the more distally situated pulmonary vessels. The bronchial capillaries then actually supply the alveoli and parts concerned. It is thus quite logical to assume that the alveoli cannot be kept dry easily because of the increased pressure in the capillaries surrounding them and so alveolar congestion occurs. With the return of oxygen, the pulmonary arteries begin to dilate again. Eventually the pressure in the pulmonary arteries is back to normal again and the blood flows normally into the pulmonary capillaries surrounding the alveoli. The decreased hydrostatic pressure provokes absorption from the alveoli and alveolar congestion (consolidation) is relieved.

Similar changes occur in atelectasis where the hypoxia flects the pulmonary and bronchial circulation. When the atelectasis is relieved and the hypoxia reversed, the pulmonary circulation works normally again.

\section{Pulmonary tuberculosis}

Because there is less blood flow in the apical regions than in the basal regions of the lung and because there is also a relatively avascular area where the bronchial blood supply ends and before the pulmonary blood supply commences, this is the area where pulmonary tuberculosis is most likely to occur - apically and in
the finer bronchioli.

\section{Pulmonary emphysema}

In this condition the calibre of the alveolar capillary network is smaller than usual, and the normal capillary structure has often disappeared. Newly developed branches from the bronchial arteries therefore anastomose with pulmonary arteries in the precapillary region (Nagaishi, 1972).

\section{Bronchiectasis}

This disease leads to a definite enlargement of the bronchial arteries and the formation of more anastamoses between the bronchial and pulmonary arteries.
The enlarged bronchial arteries are associated with the granulation tissue formed by chronic infection and with the increased metabolic needs of the hypertrophied muscle and hyperplastic lymphoid tissue that are often observed. New anastomoses also originate in the granulation tissue. The pulmonary arterial blood is shunted away from the diseased portions of the lung into relatively intact parenchyma where the pulmonary blood pressure is presumably lower. The anastomoses between the bronchial and pulmonary arteries account in part for the fact that there is little or no desaturation of the systemic arterial blood even in severe cases of bronchiectasis (Liebow et al., 1949). In severe cases the increased bronchial circulation could eventually become $20 \%$ of the cardiac output (Meyer, 1976).

\section{Liver cirrhosis and portal hypertension}

In 200 consecutive cases of cirrhosis, the incidence of hydrothorax was found to be approximately $6 \%$. There are different reasons given for this, namely hypoalbuminaemia, ascites fluid passing either into pleural space via defects in the tendinous portion of the diaphragm or transported via the lymphatic system (Johnson and Loo, 1964). However, if portal hypertension is present, then, due to collaterals between this system and the azygos system, the pressure in the azygos system will rise and the pressure in the bronchial veins that drain into the azygos system may be increased to such an extent that the pulmonary-bronchial post-capillary venous anastomoses may open. This will lead to an increased hydrostatic pressure in the pulmonary capillaries with decreased absorption of pleural fluid and thus hydrothorax will occur.

\section{Heart failure}

Right-sided heart failure is usually secondary to leftsided failure. When the right ventricle begins to fail systemic venous congestion occurs. Most of the bronchial veins drain into the right atrium and the increased pressure in these leads to an increased pressure in the pulmonary veins of the visceral pleura (through their anastomoses). The pleural fluid is not absorbed and a pleural effusion occurs.

\section{CONCLUSION}

It is generally accepted that there are connections between the systemic and pulmonary arterial systems in the lungs. These can be at intercapillary or precapillary levels. As regards the precapillary shunts, the mechanisms whereby they open are most important in understanding certain lung conditions, e.g. atelectasis, pulmonary embolus, pneumonia. These mechanisms prevent necrosis of the associated lung parenchyma and explain the phenomenon of local pleural effusions. Postcapillary (veno-venous) anastomoses are responsible for the pleural effusions seen in liver cirrhosis and rightsided heart failure.

Finally, it must be remembered that in all obscure cases of hypertrophy and failure of the right heart, the possibility of widened connections between the bronchial and pulmonary arteries should be considered (Wood and Millar, 1937/8).

\section{References}

Ganong, W. F. (1973): Review of medical physiology, 6th ed. Lange Medical Publications. Los Altos, California.

Johnston, R. F. and Loo, R. V. (1964). Hepatic hydrothorax. Ann. Int. Med., 61, $385-401$.

José, A. D. and Milner, W. K. (1959). The demonstration of arteriovenous shunts in normal human subjects and their increase in certain disease states. $J$. Clin. Invest., 38, 1915-1923. 
Last, R. J. (1972). Anatomy: Regional and applied. 5th Ed. Churchill Livingstone. Edinburgh and London.

Liebow, A. A., Hales, M. R. and Lindskog, G. E. (1949). Enlargement of the bronchial arteries and their anastomoses with the pulmonary arteries in bronchiectasis. Am. J. Path., 25, 211.

Nagaishi, C. (1972). Functional anatomy and histology of the lung. 1st Ed. Baltimore and London, University Park Press.

Meyer, B. J. (1976). Die fisiologiese basis van geneeskunde. H.A.U.M. Cape Town.

pump, K. K. (1972). Distribution of the bronchial arteries in the human lungs. Chest, 62, $447-451$.

Shedd, D. P., Alley, R. D. and Lindskog, G. E. (1951). Observations on the hemadynamics of bronchial-pulmonary vascular communications. J. Thorac. Surg., 22, $537-548$.
Tobin, C. E. (1952). The bronchial arteries and their connections with other vessels in the human lung. Surg. Gynec. and Obst., 95, $741-750$.

Tobin, C. E. (1966), Arterio-venous shunts in the peripheral pulmonary circulation in the human lung. Thorax, 21, $197-204$.

West, J. B. (1974). Respiratory physiology - the essentials. Blackwell Scientific Publication, Oxford, London, Edinburgh, Melbourne.

Wood, D. A. and Miller, M. $(1937 / 8)$. The role of the dual pulmonary circulation in various pathologic conditions of the lungs. J. Thorac. Surg., 7, 649-670.

\section{Acknowledgement}

Prof. A. D. Malan, Department of Anatomy, University of Stellenbosch. 